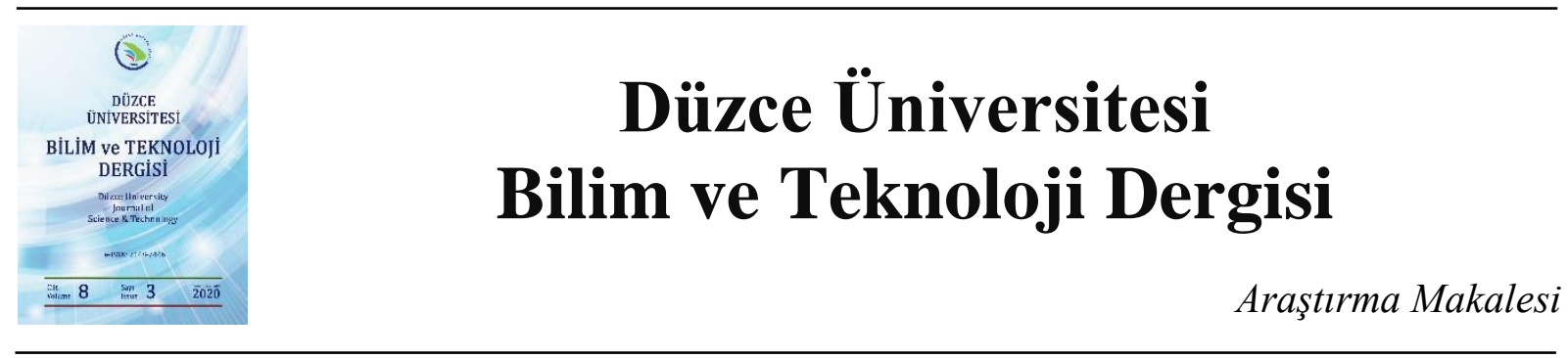

\section{Fonksiyonel Derecelendirilmiş $\mathrm{TiB}_{2} / \mathrm{Al}$ Kompozitlerin Üretimi Üzerine Bir Çalışma}

\author{
(D) Ömer SAVAŞ ${ }^{\mathrm{a}, *}$ (D) Ömer Faruk DEMİROK ${ }^{\mathrm{b}}$ \\ a, * Gemi İnşaatı ve Denizcilik Fakültesi, Yıldız Teknik Üniversitesi, Beşiktaş, İstanbul, TÜRKIYYE \\ ${ }^{b}$ Denizcilik Meslek Yüksekokulu, Sakarya Uygulamalı Bilimler Üniversitesi, Kocaali, Sakarya, TÜRKIYYE \\ * Sorumlu yazarin e-posta adresi: osavas@yildiz.edu.tr
}

DOI : $10.29130 /$ dubited.648333

\begin{abstract}
ÖZET
$\mathrm{Bu}$ çalışmada, Fonksiyonel derecelendirilmiş $\mathrm{TiB}_{2} / \mathrm{Al}$ kompozitlerin savurma döküm tekniği ile üretimi ve özelliklerinin araştırılması amaçlanmıştır. $\mathrm{TiB}_{2}$ takviye fazı, sıvı alüminyum içerisinde in-situ tekniği ile kendiliğinden oluşturulmuștur. Savurma döküm tekniğinden faydalanılarak kompozitler fonksiyonel olarak derecelendirilmiş ve son şekilleri verilmiştir. Üretilen kompozitlerin özellikleri, optik mikroskobu, SEM, XRD, yoğunluk ve sertlik analizleri kullanılarak detaylandırılmıştır. Çalışmada Al-Ti-B sistemi kullanılarak alüminyum matris içerinde in-situ tekniği ile $\mathrm{TiB}_{2}$ borür yapılarının sentezlene bildiğini görülmüsşür. Aynı zamanda kompozit malzemelerin savurma kuvveti yönünden mikro yapı özelliklerinin değiştiği ve bu değişime bağılı olarak kompozitlerin yoğunluk ve sertlik değerlerinde önemli bir değişim tespit edilmiştir. Sonuçlar aynı zamanda alüminyum matrise $\% 19 \mathrm{TiB}_{2}$ ilavesi ile $\% 83$ 'lük, \%12 $\mathrm{TiB}_{2}$ ilavesi ile de $\% 50$ 'lik sertlik artışı sağladığını göstermiştir.
\end{abstract}

Anahtar Kelimeler: Fonksiyonel derecelendirilmiş malzeme, in-situ TiB 2

\section{A Study on Production of Functionally Graded $\mathrm{TiB}_{2} / \mathrm{Al}$ Composites}

\begin{abstract}
In this study, it is aimed to investigate the production and properties of functional grade $\mathrm{TiB}_{2} / \mathrm{Al}$ composites by centrifugal casting technique. $\mathrm{TiB}_{2}$ particles were spontaneously formed in the aluminum matrix by in-situ technique. Centrifugal casting technique has been used in functional grading and final shapes of composites. The properties of the composites were detailed using optical microscopy, SEM, XRD, density and hardness analysis. It has been seen that $\mathrm{TiB}_{2}$ boride structures can be synthesized by in-situ technique in aluminum matrix using a Al-Ti-B system. At the same time, it has been determined that the microstructure properties of composite materials change into the centrifugal force direction. In addition, a significant change in density and hardness values of composites has been determined. The results also showed that the hardness of aluminum matrix increased by $83 \%$ with the addition of $19 \mathrm{wt} . \% \mathrm{TiB}_{2}$ and $50 \%$ with the addition of $12 \mathrm{wt} . \% \mathrm{TiB}_{2}$.
\end{abstract}

Keywords: Functionally graded material, in-situ $\mathrm{TiB}_{2}$

Geliş: 18/11/2019, Düzeltme: 01/04/2020, Kabul: 10/05/2020 


\section{GİRIS}

Kompozit malzemeler birbirinden farklı iki veya daha fazla malzemenin makro boyutta bir araya gelmesi ile oluşturulan malzemelerdir ve kendisini oluşturan malzemelerin en iyi özelliklerini üzerinde taşırlar. Kompozitler, matris fazına bağılı olarak metal, polimer ve seramik matrisli kompozitler şeklinde üç kategoride incelenir. Seramik matrisli kompozitler yoğunluklarının düşük olması ile birlikte aşınma dirençleri yüksektir. Ancak toklukları ve tekrarlı yükler altında mukavemetleri çok düşüktür, polimer matrisli kompozitlerin yoğunlukları çok düşük olmasına karşın mukavemet ve aşınma dirençleri çok düşüktür ve kullanım sıcaklığı $100{ }^{\circ} \mathrm{C}$ 'nin altındadır. Buna karşın metal matrisli kompozitlerin yüksek mukavemet, tokluk, aşınma direnci, termal şok direnci, korozyon direnci ve düşük yoğunluk özelliklerini bir arada bulundura bilmektedir [1-3].

Metal Matrisli Kompozitlerin (MMK) üretimi üzerine yapılan çalışmalarda, takviye fazının matris içerine ilavesi iki faklı şekilde yapıldığ 1 görülmektedir. Bunlar Ex-situ ve İn-situ yöntemleridir. Ex-situ yönteminde tevkiye fazları, sıvı metal içesine vorteks, infilitrosyon, karıştırma gibi mekanik bir etki ile doğrudan ilavesi ile yapılmaktadır. İn-situ yönteminde ise takviye fazları matris içerine ilave edilmesi, matris içerinde yer alan element veya bileşiklerin reaksiyona girmesi ile kendiliğinden oluşturmaktadır. $\mathrm{Bu}$ şekilde takviye fazının matris içerinde kendiliğinden oluşturulması ile Ex-situ üretim yönteminde karşılaşılan gözenek oluşumu, sslatılabilirdik, homojen olmayan dağılım, ara bileşiklerin oluşması gibi problemlerin önüne geçilebilmektedir. Bununla birlikte oluşan partiküllerin termodinamik olarak kararlı olduğu, kompozitin geri dönüşüme olanak sağladığı, üretimin kolay ve ucuz olduğu görülmektedir [4].

MMK'lerde matris içerisinde artan takviye oranı, kompozitlerin çekme mukavemeti, elastik modülü ve aşınma direnci gibi bir takım özelliklerini iyileştirmelerine karşın, kırılma tokluğunu önemli ölçüden kötüleştirmektedir. Fonksiyonel olarak derecelendirilmiş kompozit malzemeler (FGKM) bu problemi önemli ölçüde ortadan kaldırdığı görülmektedir. FGKM'lerin mikro yapı özellikleri belirli bir yönde ya fonksiyonel ya da katmanlı olarak değişim göstermektedir. Fonksiyonele olarak değişim gösteren FGKM'ler hem termal hem de mekanik gerilmeleri önemli ölçüde elemine etmektedir [5-9].

Ö. Savaş ve ark. [10] savurma döküm yöntemi kullanarak alüminyum matrisli $\mathrm{Al}_{3} \mathrm{Ti}$ takviyeli fonksiyonele derecelendirilmiş kompozitleri ürettiklerini belirmişlerdir. Çalışmada üretilen kompozitlerlerin mikro yapılarının savurma yönünde değiştiğini ve buna bağlı olarak kompozitin sertliğinin ve abrasif aşınma direncinin değiştiğini rapor etmişlerdir.

Elastik modülünün, aşınma dirençlerinin yüksek, ucuz olmasından dolayı, alüminyum matrisli kompozitlerin üretiminde takviye elemanı olarak $\mathrm{SiC}$ ve $\mathrm{Al}_{2} \mathrm{O}_{3}$ partikülleri yaygın olarak kullanılmaktadır. $\mathrm{TiB}_{2}$ partiküllerinin yaygın olarak kullanılan $\mathrm{SiC}$ ve $\mathrm{Al}_{2} \mathrm{O}_{3}$ 'e göre fiziksel özelliklerinin daha yüksek olması, metal matrisli kompozitlerin üretimi için çok yüksek potansiyele sahip olacağını göstermektedir [11].

M. Pul [12], Al 7075 matrisli $\mathrm{SiC}, \mathrm{B}_{4} \mathrm{C}$ ve $\mathrm{TiB}_{2}$ takviyeli kompozit malzemelerin yoğunluk, sertlik, çapraz kırılma ve aşınma gibi mekanik özelliklerini belirlemeye yönelik olarak yaptığı çalışmada toz metalürjisi tekniği kullanılarak farklı takviye oranlarda kompozit malzemeler üretmişlerdir. Çalışmada en yüksek kırılma dayanımı ile en düşük aşınma miktarı SiC takviyeli kompozitler de meydana geldiği belirtilmiş ve en yüksek sertlik ve en düşük yoğunluk değerlerinin ise $\mathrm{TiB}_{2}$ takviyeli kompozitler de gözlemlendiği rapor edilmiştir.

L. Lu [13] ve arkadaşları $\mathrm{TiB}_{2}$ partiküllerini sentezlenmesine yönelik yaptıkları çalışmada, sıvı alüminyum içerisine $850{ }^{\circ} \mathrm{C} \mathrm{K}_{2} \mathrm{TiF}_{6}$ ve $\mathrm{KBF}_{4}$ tuzlarının ilave edilmesinin ardından 5 ve 15 dakikalık iki farklı bekleme süresinin ardından katılaşmaya bırakmışlardır. Sıvı alüminyum içerinde bulunan Ti ve B'un ekzotermik reaksiyona girmesinin sonucunda $\mathrm{TiB}_{2}$ borür yapılarının kendiliğinden oluştuğunu rapor etmişlerdir. Oluşan partiküllerin altıgen bir yap1 ve bekleme süresi ile boyunda ve şeklinde değişim olmadığını belirtmişlerdir. S. Suresh [14] ve arkadaşının yaptıkları çalışmada in-situ tekniği ile üretilen $\mathrm{TiB}_{2} / \mathrm{Al}$ kompozitlerinin mekanik ve aşınma özelliklerin daha iyi olduğunu rapor etmişlerdir. K.L. Tee 
[15] ve arkadaşları yapmış oldukları çalışmada alüminyum alaşım içerisine titanyum ve bor tozları karıştırarak in-sitü $\mathrm{TiB}_{2}$ partiküllerini oluşturduklarını rapor etmişlerdir. Elde ettikleri kompozit malzemelerde $\mathrm{TiB}_{2}$ partiküllerinin boyutunun 1-3 $\mu \mathrm{m}$ olduğu ve alüminyum içerisine $\% 15 \mathrm{TiB}_{2}$ ilavesi ile mukavemet artışının \%57, akma dayanımı \%66 ve elastik modülünün $\% 22$ oranında olduğunu belirtmişlerdir.

Ö. Savaş ve ark.[16] alüminyum matrisli $\mathrm{TiB}_{2}$ takviyeli fonksiyonele derecelendirilmiş kompozitleri savurma döküm yöntemi kullanarak ürettiklerini rapor etmişlerdir. Yapılan bu çalışmada $\mathrm{TiB}_{2} / \mathrm{Al}$ kompozitin sertlik ve aşınma direncinin savurma yönünde fonksiyonel bir şekilde değiştiğini belirtmişlerdir.

Yapılan önceki çalışmalarında fonksiyonel derecelendirilmiş in-situ $\mathrm{TiB}_{2} / \mathrm{Al}$ kompozit malzemeleri ile ilgili olarak çok az sayıda çalışma yapıldığı görülmektedir $[17,18]$ Bu nedenle bu çalışmada amacımız, in-situ tekniği ile $\mathrm{TiB}_{2}$ partikülleri sıvı matris içerinde kendiliğinden oluşturmak ve savurma döküm yöntemi kullanarak $\mathrm{TiB}_{2} / \mathrm{Al}$ FGK malzemeleri üretmek ve özelliklerini araştırmaktır.

\section{MATERYAL VE METOT}

Yapılan çalışmada $\mathrm{TiB}_{2} / \mathrm{Al}$ FDK malzemeler iki aşamada üretilmiştir. Bu aşamalar sırasıyla, in-situ $\mathrm{TiB}_{2}$ partiküllerinin sıvı alüminyum içerisinde sentezlenmesi ve savurma döküm tekniği ile kompozitlere nihai şekillerinin verilmesidir.

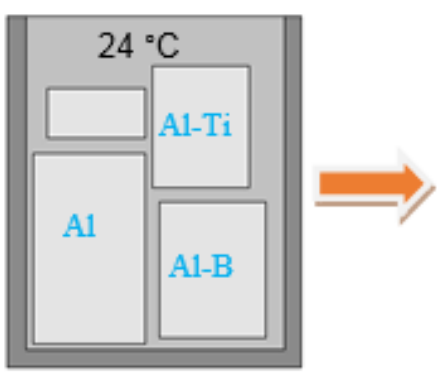

$\mathrm{TiB}_{2}$ 'ce zengin bölge $\mathrm{b}$

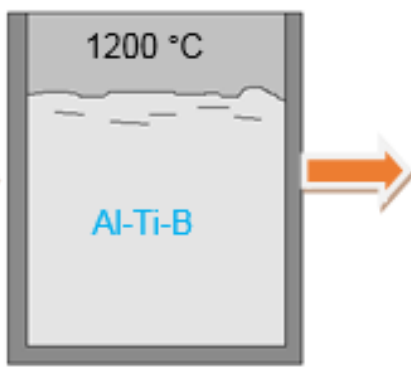

c

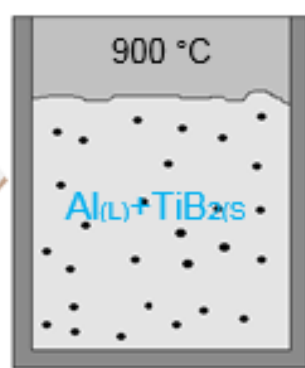

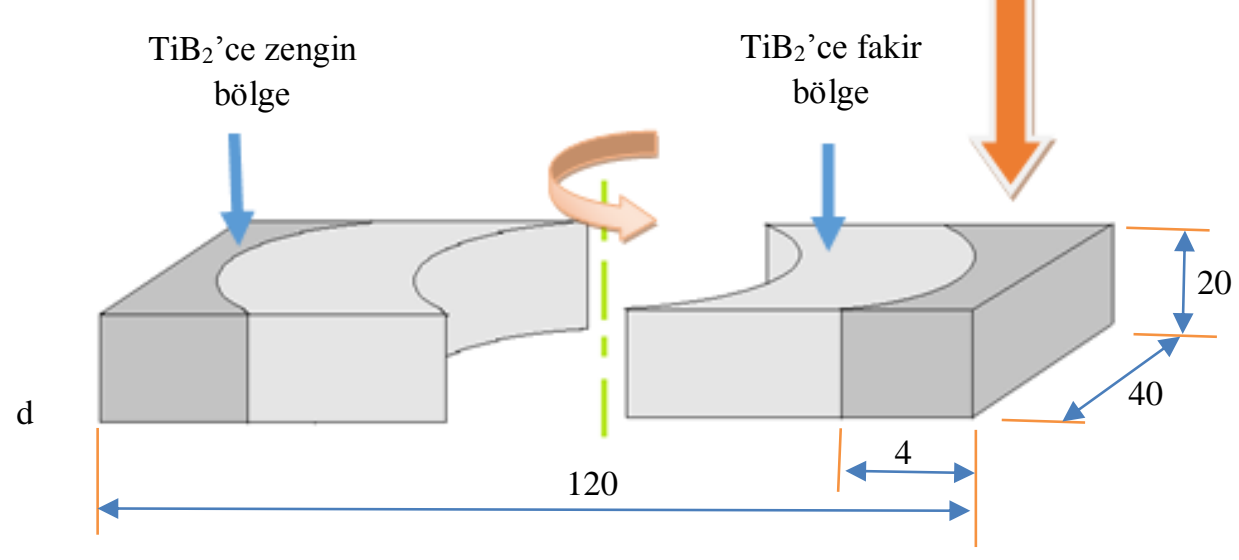

Şekil 1.TiB $/$ /Al FGKM üretim şeması

$\mathrm{TiB}_{2}$ partiküllerinin oluşturulmasında başlangıç malzemesi olarak alüminyum alaşımlarının dökümünde tane inceltici olarak kullanılan ticari Al-10Ti ve Al-2B alaşımları seçilmiştir [19,20]. Kompozit üretiminde kullanılan alaşımlar ve kimyasal kompozisyonu Tablo 1'de görülmektedir. 
Tablo 1. Kompozit üretiminde kullanılan külçeler ve onlarının kimyasal kompozisyonu

\begin{tabular}{|l|l|l|l|l|l|l|l|l|l|}
\hline \multirow{2}{*}{ Alaşım } & \multicolumn{9}{|l}{ Element, Ağ..\% } \\
\cline { 2 - 10 } & $\mathrm{Ti}$ & $\mathrm{B}$ & $\mathrm{Fe}$ & $\mathrm{Si}$ & $\mathrm{Mn}$ & $\mathrm{Mg}$ & $\mathrm{Cr}$ & $\mathrm{Cu}$ & $\mathrm{Al}$ \\
\hline Saf Al & 0,001 & 0.000 & 0.301 & 0.116 & 0.026 & 0.009 & 0.000 & 0.000 & Kalan \\
\hline Al-Ti & 9.851 & 0.000 & 0.225 & 0,192 & 0.203 & 0.000 & 0.014 & 0.003 & Kalan \\
\hline Al-B & 0.009 & 1.980 & 0.151 & 0.128 & 0.088 & 0.001 & 0.017 & 0.001 & Kalan \\
\hline
\end{tabular}

Şekil 1'de $\mathrm{TiB}_{2} / \mathrm{Al}$ FGKM üretim şemas1 görülmektedir. $\mathrm{TiB}_{2}$ borür yapılarının sentezlenmesi aşamasında ilk olarak, \%3 ve \%1,3 oranında B ve Ti içerecek şekilde (Şekil 1a'da görülmektedir) ticari Al-10Ti ve Al-2B külçeleri saf alüminyum külçeleri ile çelik pota içerisine konulmuştur. Külçelerin ergiyerek tamimiyle sıvı Al-Ti-B çözeltisine dönüşmesi için külçeler bir direnç ergitme fırın içerisinde $1200^{\circ} \mathrm{C}$ 'de 60 dakika bekletilmiştir. Yapıda oluşması istenmeyen $\mathrm{Al}_{3} \mathrm{Ti}$ ve $\mathrm{AlB}_{2}$ partikülleri yerine $\mathrm{TiB}_{2}$ partiküllerinin oluşması için Şekil lb ve 1c'de görüldüğü gibi $1200{ }^{\circ} \mathrm{C}$ 'de ki Al-Ti-B ergiyi $900{ }^{\circ} \mathrm{C}$ 'ye alınmış ve bu sıcaklıkta 30 dakika beklenmiştir. Şekil 2 'de çelik pota içerinde $900{ }^{\circ} \mathrm{C}$ 'de $\mathrm{ki}$ ' $\mathrm{Al}_{(\mathrm{svvl})}+$ $\mathrm{TiB}_{2(\mathrm{~kat} \text { ) }}$ ' yarı katı çözeltisinin çelik pota içerisindeki görüntüsü verilmektedir. ' $\mathrm{Al}_{(\mathrm{svvl})}+\mathrm{TiB}_{2(\mathrm{kat1})}$ ' yar1katı eriyiği savurma işlemi için bir çelik savurma kalıbına alınarak savurma döküm mekanizması içerinde katılaşıncaya kadar 2000 rpm dönme hızında savrulmuştur. Kompozit üretiminde kullanılan çelik potlar ve kalıpların sıvı alüminyum ile reaksiyona girmemesini engellemek amacı ile iç yüzeyleri bor nitrür $(\mathrm{BN})$ ile kaplanmıştır.

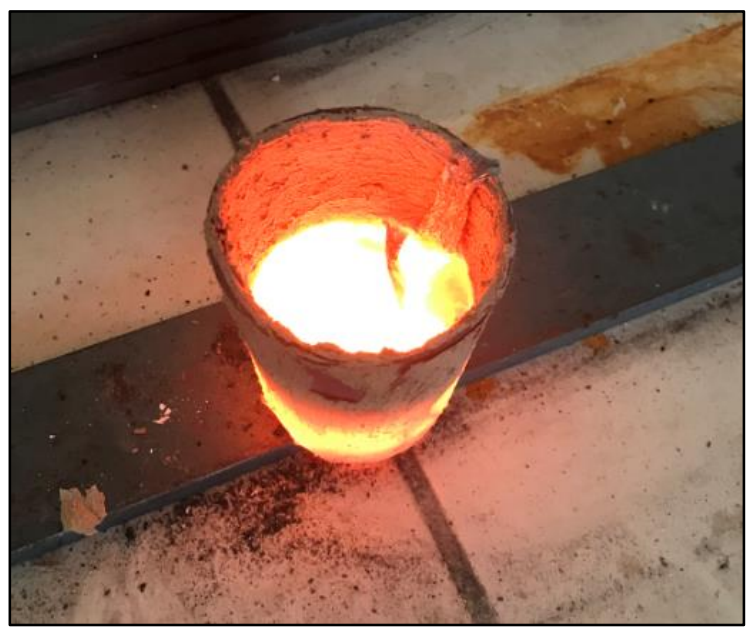

Şekil 2. Çelik pota içerinde $900^{\circ} \mathrm{C}$ 'de ki 'Al(sıvı) + TiB $B_{2}(k a t ı)$ 'yarı katı çözeltisinin çelik pota içerisindeki görüntüsü

Nihai kompozitlerinin kalıp dış cidarından içeriye doğru $\mathrm{TiB}_{2}$ 'ce zengin ve $\mathrm{TiB}_{2}$ 'ce fakir bölgelerin yer alacığı varsayılarak Şekil 3'de temsili resimde gösterildiği gibi karakterizasyon çalışmaları için kompozit malzemelerin diş yüzeyinden içeriye doğru $0 \mathrm{~mm}, 3 \mathrm{~mm}$ ve $5 \mathrm{~mm}$ mesafelerden numuneler alınmıştır. Bu bölgeler dış, orta ve iç bölgeler şeklinden isimlendirilmiştir. 


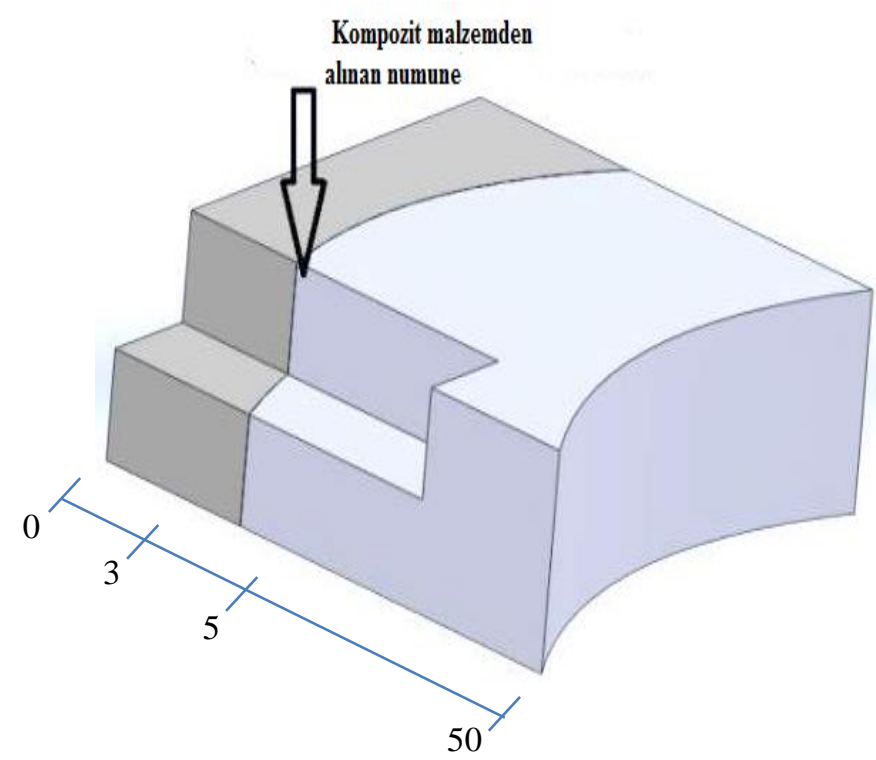

Şekil 3. Üretilen kompozit malzemeden alınan numunenin temsili görüntüsü

Optik analizler için üretilen kompozitler üzerinden alınan numuneler sırası ile 150, 400, 600, 1000 ve 1200 mesh SiC zımparalama işlemi sonrasında $0,2 \mu$ m'luk elmas pasta süspansiyonu ile 15 dakika parlatılmıştır. Mikro yapısal analiz için Clemex Vision görüntü analiz sistemi ile donatılmış bir Olympus optik mikroskop kullanılmıştır. Ayrıca aynı bölgelerde birbirine eş değer birer numuneler daha alınarak taramalı elektron mikroskopu(SEM) ile incelenmiştir. $\mathrm{TiB}_{2}$ yapısının detaylı olarak değerlendirilmesi amacıyla, hazırlanan numuneler $\% 10 \mathrm{HCl}$ solüsyonu kullanılarak derin dağlama yapılmış ve sonrasında JEOL JSM 6060LV taramalı elektron mikroskop (SEM) görüntüsü alınmıştır. Oluşan bileşiklerin belirlenmesi amaciyla ve detaylı incelenmesi için X-Ray difraktometre (XRD, D8 ADVANCE Da Vinci) cihazı kullanılmıştır.

Sertlik analizi yapılmadan önce deney yapılacak bölge bu deney için uygun hâle getirilmiştir. Sertlik testleri için en kaba zımparadan başlanarak 1200 mesh zımparaya kadar yüzeyleri temizlenmiş ardından parlatılmıştır. Sertlik değerleri Brinell sertlik ölçme tekniği kullanılarak yapıldı. Bu çalışmada 62,5 kN'lik bir kuvvet uygulanarak 2,5 mm çaplı bir bilye yardımıyla malzemelerin sertlik değerleri alınmıştır.

\section{ARASTTIRMA SONUCLARI VE TARTISMA}

Savurma işlemi neticesinde üretilen kompozitlerin $\mathrm{TiB}_{2}$ 'ce fakir ve zengin iki farklı alana sahip olduğu görülmüştür. Kompozitlerin karakterizasyonu için $\mathrm{TiB}_{2}$ 'ce zengin alan iki farklı bölgeye ayrılmıştır (dış ve orta bölge şeklinde). TiB ${ }_{2}$ 'ce fakir alan ise bir bölgeye ayrılmıştır (iç bölge). Şekil 4'de üretilen kompozitlerin dış, orta ve iç bölgelerinden alınan numunelere ait mikro yapı görüntüsü verilmiştir. Şekil $4 \mathrm{TiB}_{2}$ partiküllerinin yoğunluğunun orta bölgeye göre daha yüksek olduğu görülmektedir. Şekil 4c'de iç bölgede ise hiç $\mathrm{TiB}_{2}$ partikülünün olmadığı dikkate çelmektedir. Bunun muhtemel nedeni savurma kuvvetinin etkisi ile yoğunluğu sıvı alüminyuma $\left(2,37 \mathrm{~g} / \mathrm{cm}^{3}\right)$ göre saha yüksek olan $\mathrm{TiB}_{2}$ partiküllerinin $\left(4,5 \mathrm{~g} / \mathrm{cm}^{3}\right)$ kompozitin dış bölgelere doğru sürüklenmesinden kaynaklandığı varsayılmaktadır. Şekil 4 a ve b'de, $\mathrm{TiB}_{2}$ partiküllerinin homojen bir dağ 1 lım yerine tane sınırları boyunca ağ şeklinde kümelenmiş olduğu görülmektedir. Bu durumun muhtemel nedeni katılaşma sırasında katı $\alpha$ - Al'nin boyutları çok küçük olduğu için katı $\mathrm{TiB}_{2}$ partiküllerini sıvı bölgeye itmesinden kaynaklandığı düşünülmektedir $[18,21]$. 



Şekil 4. Üretilen kompozitlerin dlş yüzeyinden içeriye doğru a) $0 \mathrm{~mm}$ (dlş bölgeden), b) $3 \mathrm{~mm}$ (orta bölgeden) ve c) $5 \mathrm{~mm}$ (iç bölgeden) mesafeden alınan mikro yapı görüntüsü

Şekil 5 ve Şekil 6'de döküm numunesi üzerinden alınan $\mathrm{TiB}_{2}$ 'ce fakir ve zengin bölgelere ait XRD analiz sonuçları verilmiştir. Alınan XRD analizlerinde kompozitin iç kısımlarında sadece alüminyum piklerinin mevcut olduğu görülmektedir (Şekil 5). Kompozitin $\mathrm{TiB}_{2}$ 'ce zengin dış bölgelerinden alınan XRD sonucuna göre alüminyum piklerinin yanında $\mathrm{TiB}_{2}$ piklerinin yer aldığı görülmektedir( Şekil 6). $\mathrm{Bu}$ sonuca göre sıvı alüminyum içeresinde oluşan katı $\mathrm{TiB}_{2}$ borür yapıların savurma kuvvetinin etkisi ile kalıp iç kısmından dışarıya doğru savrulduğun görülmektedir. Siyah bölgeden alına XRD sonucunda ise yapıda yalnız $\mathrm{Al}$ ve $\mathrm{TiB}_{2}$ pikinin görülmesi sistemde mevcut olan titanyum ve borun tamamının ekzotermik reaksiyona girerek $\mathrm{TiB}_{2}$ bileşiğini oluşturduğunu göstermektedir ve üretim aşamasında belirlenen Ti/B oranının uygun olduğunu göstermiştir. Alınan XRD analizleri sonucuna göre fakir bölgelerde $\mathrm{TiB}_{2}$ oranın sıfıra yakın olduğu, $\mathrm{TiB}_{2}$ 'ce zengin bölgelerde ise $\% 14$ civarında olduğu tespit edilmiştir. 


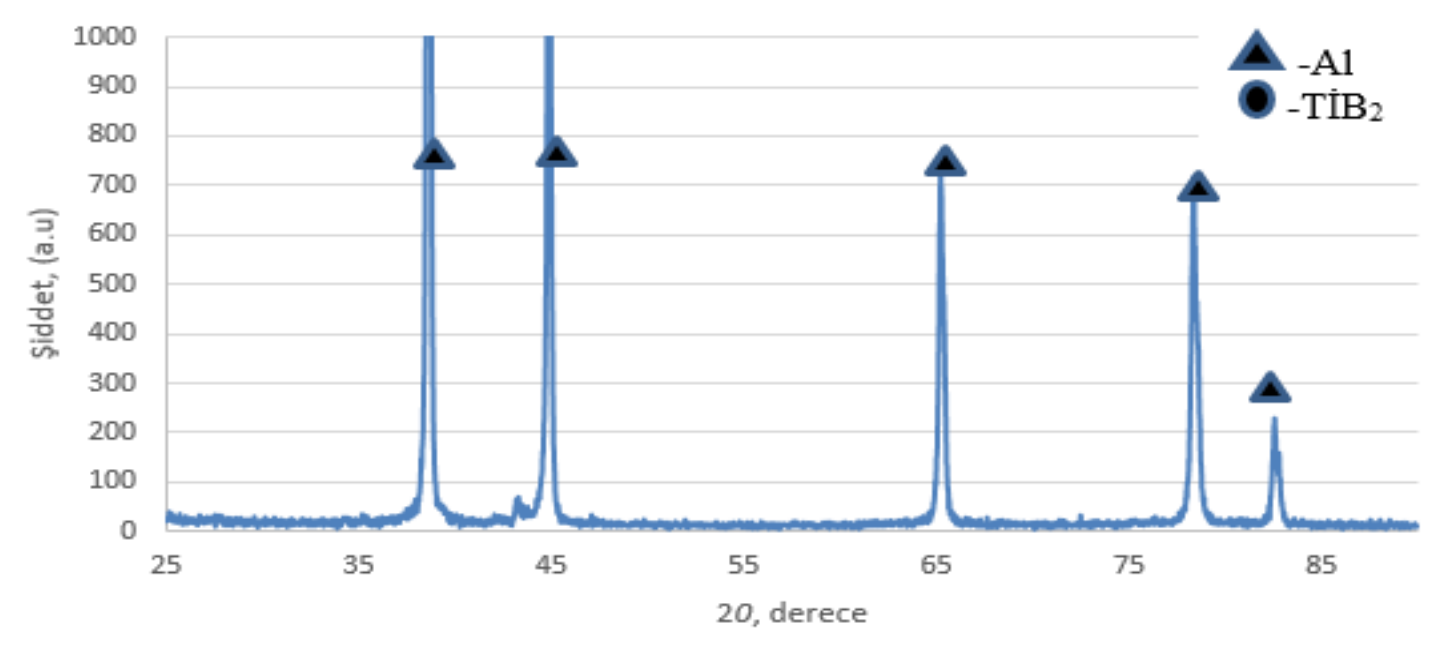

Şekil 5. TiB2 'ce fakir bölgeye ait XRD analiz sonuçları

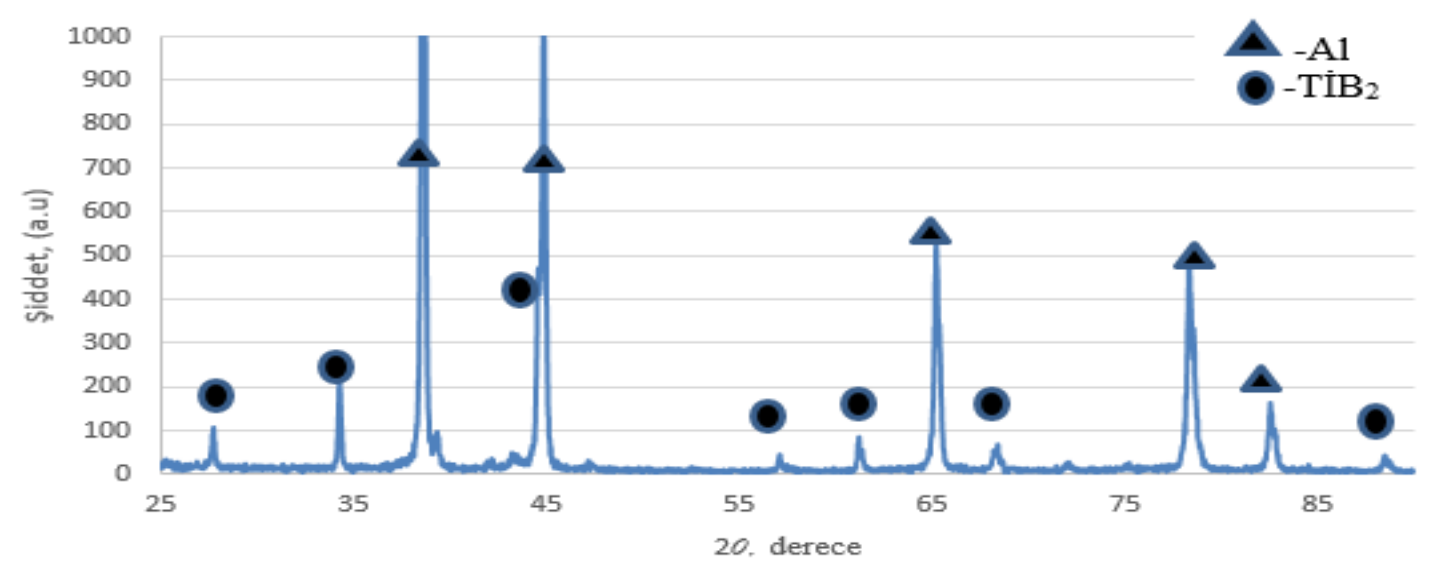

Şekil 6. TiB 'ce zengin bölgeye ait XRD analiz sonuçları

Şekil 7'de $\mathrm{TiB}_{2}$ 'ce zengin ve $\mathrm{TiB}_{2}$ 'ce fakir bölgelerden alınan SEM görüntüleri verilmiştir. Şekilde $\mathrm{TiB}_{2}$ 'ce zengin bölgede alüminyum matris içerisinde gömülmüş $\mathrm{TiB}_{2}$ partikülleri görülmektedir. Şekil $7 \mathrm{~b}$ 'de ise $\mathrm{TiB}_{2}$ 'ce fakir olarak atfedilen bölgede neredeyse hiç $\mathrm{TiB}_{2}$ yapısının yer almadığ dikkati çekmektedir. Şekil 7a'da ayrıca $\mathrm{TiB}_{2}$ partiküllerinin boyutunun 1 mikronun altında olduğu ve $\mathrm{TiB}_{2}$ partikülleri ile alüminyum matris arasında ara bileşiklerinin yer almadığı görülmektedir. Aynı zamanda yapıda muhtemel olması beklenen kolonsal $\mathrm{Al}_{3} \mathrm{Ti}$ ve $\mathrm{AlB}_{2}$ yapılarının hiç bulunmadığını dikkati çekmektedir. Bu sonuçlar birçok çalışmada rapor edildiği gibi aşağıdaki reaksiyonların gerçekleştiğini göstermektedir [22-24].

$\mathrm{Ti}+3 \mathrm{Al} \rightarrow \mathrm{Al}_{3} \mathrm{Ti}$

$\mathrm{Al}_{3} \mathrm{Ti}+2 \mathrm{~B} \rightarrow \mathrm{TiB}_{2}+3 \mathrm{Al}$

$\mathrm{AlB}_{2}+\mathrm{Al}_{3} \mathrm{Ti} \rightarrow \mathrm{TiB}_{2}+4 \mathrm{Al}$ 

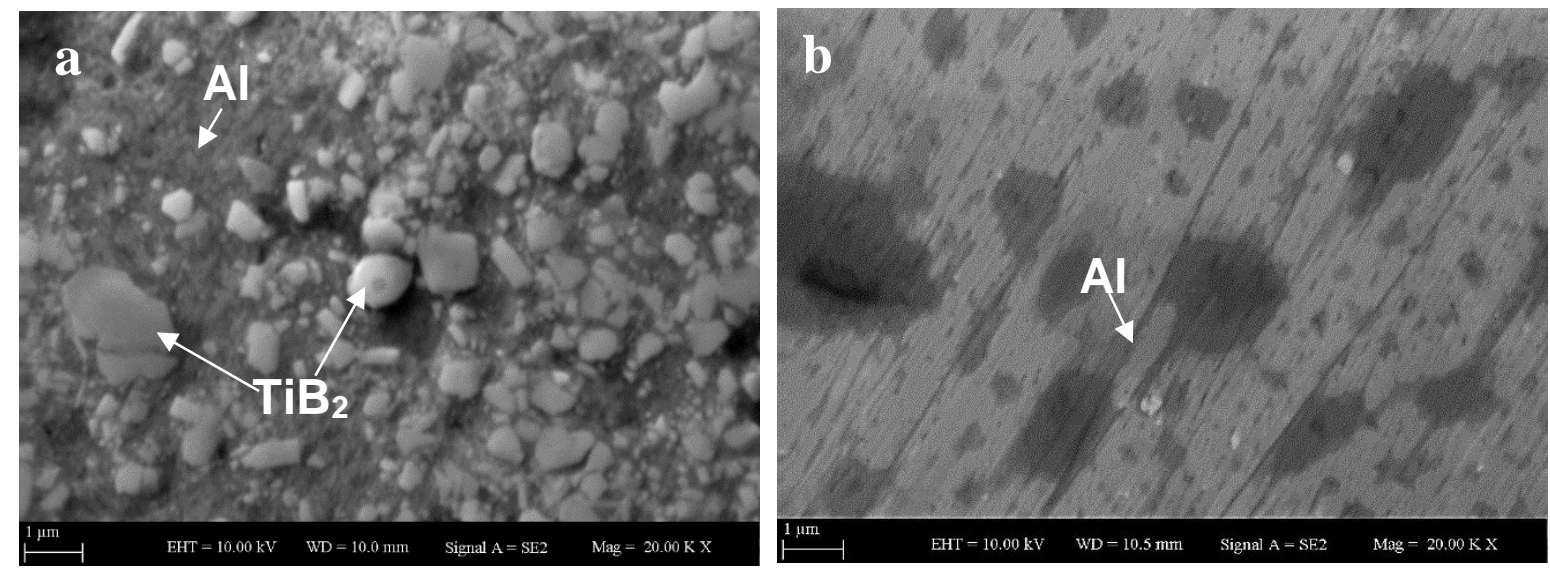

Şekil 7. a) TiBz'ce zengin ve b) fakir bölgelere ait SEM görüntüsü

Şekil 8'de $\mathrm{TiB}_{2}$ 'ce zengin bölgenin \%10 HCI çözeltisi ile 30 sn. dağlaması sonrasında alınan bir SEM görüntüsü verilmiştir. Dağlama sonrasında matris alaşımı olan alüminyumun tamamı HCI çözeltisi tarafından çözünmüş olduğu ve $\mathrm{TiB}_{2}$ partiküllerinin ise çözünmediği ve hatta dejenerasyona uğramadığ görülmektedir. Partiküllerin şeklinin yuvarlak olmayıp pul şeklinde olduğu dikkati çekmektedir. Ayrıca partiküllerin genişlikleri ve kalınlıkları birbirinden farklı olup genişlik ve kalınlık arasında yaklaşık 3 katlık bir farkın söz konusu olduğu görülmektedir.

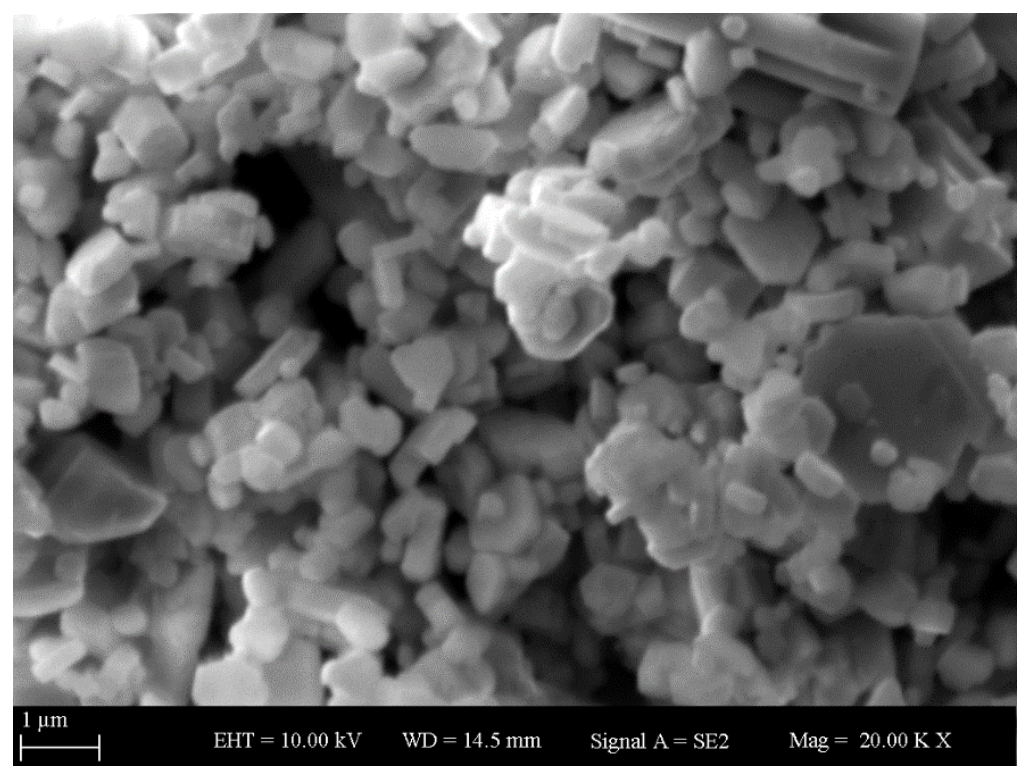

Şekil 8. TiB2 'ce zengin bölgenin \%10 HCI çözeltisi ile derin dağlama sonrasinda alınan SEM görüntüsü

Tablo 2. Üretilen kompozitlerin dış, orta ve iç bölgelerine ait yoğunluk, takviye oranı ve sertlik değerleri

\begin{tabular}{lccc}
\hline \multirow{2}{*}{ Bölgeler } & Yoğunluk & Takviye oranı & Sertlik \\
\cline { 2 - 4 } & $\mathrm{g} / \mathrm{cm}^{3}$ & Ağ.\% & $\mathrm{HB}$ \\
\hline Dış Bölge & 3,07 & 19,00 & 62,4 \\
\hline Orta Bölge & 2,98 & 12,00 & 51,3 \\
\hline İç Bölge & 2,70 & 0,00 & 34,0 \\
\hline
\end{tabular}

Tablo 2'de üretilen kompozitlerin dış, orta ve iç bölgelerine ait yoğunluk, takviye oranı ve sertlik değerleri verilmiştir. Üretilen kompozitlerin yoğunluklarının iç bölgelerden dış bölgelere doğru arttığ Şekil 3'de görülmektedir. D1ş bölgelerde 3,07 g/ $\mathrm{cm}^{3}$ olan yoğunluk değerleri, orta bölgede 2,98 g/ $/ \mathrm{cm}^{3}$ 'e 
ve iç bölgede ise $2,70 \mathrm{~g} / \mathrm{cm}^{3}$ 'e düşmüştür. Tabloda yoğunluk değerlerinin artmasına bağılı olarak kompozitlerin takviye oranlarınındı arttığı görülmektedir. En yüksek takviye oranı ağırlıkça dış bölgelerde \% 19 iken en düşük takviye oranı iç bölgede yaklaşık sıfır olarak ölçülmüştür. Karşımlar kuralına göre matris içeride artan yüksek yoğunluklu takviye oranına bağılı olarak kompozitlerin yoğunluğunun arttığı rapor edilmektedir [25]. Yoğunluk değerlerindeki bu artışının muhtemel nedeni olarak alüminyuma göre yoğunluğu daha yüksek olan $\mathrm{TiB}_{2}$ partiküllerinden kaynaklanmıştır.

Tabloda ayrıca kompozitlerin sertlik değerlerinin iç bölgelerden dış bölgelere doğru arttı görülmektedir. En yüksek sertlik değeri \%19 $\mathrm{TiB}_{2}$ partikülleri ile güçlendirmiş bölgelerde yaklaşı $62,40 \mathrm{HB}$ olarak ölçülmüş, onu \%12 $\mathrm{TiB}_{2}$ ile güçlendirilmiş bölgelerde 51,3 HB olarak ölçülmüştür. En düşük sertlik değeri ise $\mathrm{TiB}_{2}$ partiküllerinin içermeyen iç bölgelerde $34,00 \mathrm{HB}$ olarak ölçülmüştür. Bu sertlik artışının muhtemel nedeni alüminyum matris içerine ilave edilen TiB2 partiküllerinin dislokasyon yoğunluğunu artırarak sertlik değerini artırmasından kaynaklandığı düşünülmektedir [26]. Sonuçlar alüminyum matrise $\% 19 \mathrm{TiB}_{2}$ ilavesi ile $\% 83$ oranında, $\% 12 \mathrm{TiB}_{2}$ ilavesi ile de $\% 50$ oranında sertlik artış sağladığını göstermektedir. Buna benzer şekilde Kumar ve ark [27], yaptıkları çalışmasa Al-7Si matris içerinde \%5 ve $\% 10$ oranında $\mathrm{TiB}_{2}$ partiküllerinin ilavesi ile sırası ile $\% 49$ ve $\% 108$ 'lik sertlik artışı sağladıkları rapor etmişlerdir. Kumar ve ark. [28] başka bir çalışmalarında AA7075 alüminyum alaşımı sertlik değerini $\% 5 \mathrm{TiB}_{2}$ ilavesi ile 55Hv'de $74 \mathrm{Hv}$ 'ye çıkardıklarını rapor etmişlerdir.

\section{GENEL SONUCCLAR}

Fonksiyonel derecelendirilmiş $\mathrm{TiB}_{2}$ takviyeli alüminyum matrisli kompozitlerin üretimi ve özelliklerinin deneysel araştırılmasına yönelik olarak yapılan bu çalışmada araştırma sonuçları aşağıda maddeler halinde özetlenmiştir;

1- Sonuçlar yapılan çalışmada in-situ tekniği $\mathrm{TiB}_{2}$ partiküllerinin başarılı bir şekilde matris içerisinde kendiliğinin sentezlene bildiğini göstermiştir. Sentezlenen $\mathrm{TiB}_{2}$ partiküllerinin boyutunun 1 mikronun altında ve pul şeklinde olduğu tespit edilmiştir.

2- Üretilen Kompozitlerin $\mathrm{TiB}_{2}$ 'ce zengin ve fakir iki bölgeye sahip oldukları tespit edilmiştir. $\mathrm{TiB}_{2}$ 'ce zengin bölgelerde takviye oranı dış bölgelerde $\% 19$, orta bölgelerde $\% 12$ civarında olduğu görülmüsștür. $\mathrm{TiB}_{2}$ 'ce fakir bölgelerde ise $\mathrm{TiB}_{2}$ partiküllerinin ise yok denecek kadar az olduğu tespit edilmiştir.

3- Kompozitlerin yoğunluklarının ve sertliklerinin kompozitin iç bölgelerinden dış bölgelerine doğru arttığ 1 tespit edilmiştir. Yaklaşık $34 \mathrm{HB}$ olan saf alüminyumun sertlik değerinin $\% 19 \mathrm{TiB}_{2}$ ilavesi 62,4 HB'ye ve \%12 $\mathrm{TiB}_{2}$ ilavesi ile de 51,3 HB'ye yükselttiği belirlenmiştir.

TEȘEKKÜR: Bu çalışma TÜBİTAK 1919B011702249 numaralı 2209 - A Üniversite Öğrencileri Araştırma Projeleri Destekleme Programı kapsamda desteklenmiştir. Desteklerinden dolayı TÜBİTAK'a teşekkür ederiz.

\section{KAYNAKLAR}

[1] D. B. Miracle, "Metal Matrix Composites - From Science to Technological Significance," Composites Sci. and Tec., vol. 65, pp. 2526-2540, 2005.

[2] M. Rosso, "Ceramic and Metal Matrix Composites: Routes and Properties," J. Mater. Process. Technol., vol. 175, no. 1-3, pp. 364-375, 2006.

[3] F. Aydın ve M. A. Erden, "Fe Matrisli Kompozitlerin Oda ve Yüksek Sıcaklıklardaki 
Elektrokimyasal Korozyon Davranışının İncelenmesi," Düzce Üniversitesi Bilim ve Teknol. Derg., c. 8, ss. 418-427, 2020.

[4] S. C. Tjong ve Z. Y. Ma, "Microstructural and Mechanical Characteristics of In-Situ Metal Matrix Composites," Mater. Sci. Eng. R Reports, vol. 29, no. 3, pp. 49-113, 2000.

[5] M. Naebe ve K. Shirvanimoghaddam, "Functionally Graded Materials: A Review of Fabrication and Properties," Appl. Mater. Today, vol. 5, pp. 223-245, 2016.

[6] R. Singh, V. Bhavar, P. Kattire, S. Thakare, S. Patil, ve R. K. P. Singh, "A Review on Functionally Gradient Materials (FGMs) and Their Applications," IOP Conf. Ser. Mater. Sci. Eng., vol. 229, no. 1, pp. 0-9, 2017.

[7] T. P. D. Rajan ve B. C. Pai, "Processing of Functionally Graded Aluminium Matrix Composites by Centrifugal Casting Technique," Mater. Sci. Forum, vol. 690, pp. 157-161, 2011.

[8] Y. Watanabe, Q. Zhou, H. Sato, T. Fujii ve T. Inamura, "Microstructures of $\mathrm{Al}^{-\mathrm{Al}_{3} \mathrm{Ti}}$ Functionally Graded Materials Fabricated by Centrifugal Solid-Particle Method and Centrifugal In-Situ method," Jpn. J. Appl. Phys., vol. 56, no. 1, pp. 0-11, 2017.

[9] L. Bin Niu, J. M. Zhang ve X. L. Yang, "In-situ Synthesis of $\mathrm{Al}_{3}$ Ti Particles Reinforced AlBased Composite Coating," Trans. Nonferrous Met. Soc. China (English Ed.), vol. 22, no. 6, pp. 1387-1392, 2012.

[10] Ö. Savaş ve M. S. Başer, "Investigation of Abrasive Wear Behaviour of Functional $\mathrm{Grade}^{\mathrm{Al}_{3} \mathrm{Ti}}$ Reinforced Aluminium Matrix Composites by Taguchi Approach" Bayburt Üniversitesi Fen Bilimleri Dergisi, c. 2, s. 2, 2019.

[11] X. Wang, R. Brydson, A. Jha ve J. Ellis, "Microstructural Analysis of Al Alloys Dispersed with $\mathrm{TiB}_{2}$ Particulate For MMC Applications," J. Microsc., vol. 196, no. 2, pp. 137-145, 1999.

[12] N. Engin ve Z. Erman, "Doğadan Esinlenen Optimizasyon Algoritmaları ve Optimizasyon Algoritmalarının Optimizasyonu," Düzce Üniversitesi Bilim ve Teknol. Derg., c. 4, ss. 293-304, 2016.

[13] L. Lu, M. O. Lai ve F. L. Chen, "Al-4 wt\% Cu Composite Reinforced with In-situ TiB 2 Particles," Acta Mater., vol. 45, no. 10, pp. 4297-4309, 1997.

[14] S. Suresh ve N. S. V. Moorthi, "Aluminium-Titanium Diboride (Al-TiB 2 ) Metal Matrix Composites: Challenges and Opportunities," Procedia Eng., vol. 38, pp. 89-97, 2012.

[15] K. L. Tee, L. Lu ve M. O. Lai, "In situ Stir Cast Al-TiB ${ }_{2}$ Composite: Processing and Mechanical Properties ," Mater. Sci. Technol., vol. 17, no. 2, pp. 201-206, 2010.

[16] Ö. Savaş ve Ö. Demirok, "Fonksiyonel Derecelendirilmiş $\mathrm{TiB}_{2} / \mathrm{Al}$ Kompozitlerin Abrasif Aşınma Davranışları Üzerine Deneysel Bir Çalışma," Eur. J. Sci. Technol., s. 17, ss. 972-981, 2019.

[17] S. Kumar, V. Subramaniya Sarma ve B. S. Murty, "Functionally Graded Al Alloy Matrix In-Situ Composites," Metall. Mater. Trans. A Phys. Metall. Mater. Sci., vol. 41, no. 1, pp. 242-254, 2010.

[18] M. F. Forster, R. W. Hamilton, R. J. Dashwood ve P. D. Lee, "Centrifugal Casting of Aluminium Containing In-Situ Formed TiB,," Mater. Sci. Technol., vol. 19, no. 9, pp. 1215-1219, 2003.

[19] İ. Arslan, E. Gavgalı ve M. Çolak, "Kum Kalıba Dökülen Farklı Alüminyum Alaşımlarının Dökümünde A15Ti1 B ve Al10Sr İlavesinin Mikroyapı Özelliklere Etkisinin İncelenmesi," Acad. Platf. J. Eng. Sci., c. 7, s. 2, ss. 237-244, 2019.

[20] M. Çolak ve R. Kayıkc1, “Alüminyum Dökümlerinde Tane İnceltme,” SAÜ Fen Bilim. Enstitüsü Derg. Fen Bilim. Enstitüsü Derg., c. 13, s. 1, ss. 11-17, 2009.

[21] J. Hashim, L. Looney ve M. S. J. Hashmi, "Particle Distribution in Cast Metal Matrix Composites - Part I,” J. Mater. Process. Technol., vol. 123, no. 2, pp. 251-257, 2002. 
[22] C. S. Ramesh, S. Pramod ve R. Keshavamurthy, "A study on Microstructure and Mechanical Properties of Al 6061-TiB 2 In-situ Composites," Mater. Sci. Eng. A, vol. 528, no. 12, pp. 41254132, 2011.

[23] S. Lakshmi, L. Lu ve M. Gupta, "In-situ Preparation of $\mathrm{TiB}_{2}$ Reinforced Al Based Composites," J. Mater. Process. Technol., vol. 73, no. 1-3, pp. 160-166, 1998.

[24] M. Emamy, M. Mahta ve J. Rasizadeh, "Formation of $\mathrm{TiB}_{2}$ Particles During Dissolution of TiAl3 in Al-TiB 2 Metal Matrix Composite using an In-Situ Technique," Compos. Sci. Technol., vol. 66, no. 7-8, pp. 1063-1066, 2006.

[25] S. J. Zhu ve T. lizuka, "Fabrication and Mechanical Behavior of Al Matrix Composites Reinforced with Porous Ceramic of In-Situ Grown Whisker Framework," vol. 354, pp. 306-314, 2003.

[26] S. Chatterjee, A. Ghosh ve A. Basu Mallick, "Understanding the Evolution of Microstructural Features in the In-Situ Intermetallic Phase Reinforced Al/Al 3 Ti Nanocomposite," Mater. Today Proc., vol. 5, no. 3, pp. 10118-10130, 2018.

[27] S. Kumar, M. Chakraborty, V. Subramanya Sarma ve B. S. Murty, "Tensile and Wear Behaviour of In-Situ Al-7Si/TiB 2 Particulate Composites," Wear, vol. 265, no. 1-2, pp. 134-142, 2008.

[28] V. K. V. Meti, S. Shirur, J. Nampoothiri, K. R. Ravi, ve I. G. Siddhalingeshwar, "Synthesis, Characterization and Mechanical Properties of AA7075 Based MMCs Reinforced with $\mathrm{TiB}_{2}$ Particles Processed Through Ultrasound Assisted In-Situ Casting Technique," Trans. Indian Inst. Met., vol. 71, no. 4, pp. 841-848, 2018. 